\title{
TEORES DE FÓSFORO POTENCIALMENTE DISPONÍVEL NO SOLO E ABSORVIDOS POR PLANTAS DE MANDIOCA SOB DIFERENTES FONTES DE ADUBAÇÃO EM ÁREA DE AGRICULTURA FAMILIAR
}

\author{
PIMENTEL, Marcelo Laranjeira ${ }^{1}$ \\ REIS, Iolanda Maria Soares ${ }^{2}$ \\ PORTELA, Victor Sousa ${ }^{1}$ \\ ROMANO, Maria Lita Padinha Correa ${ }^{1}$
}

\begin{abstract}
RESUMO: Objetivou-se com este estudo avaliar a taxa de absorção de fósforo na mandioca ( Manihots Esculenta Crantz) e teores de fósforo potencialmente disponíveis no solo sob diferentes fontes de adubação. O experimento foi realizado na comunidade de Boa Esperança utilizando a cultivar Bem-te-vi, no delineamento em blocos casualizados com 4 tratamentos: T1 (sem adubação), T2 (adubação NPK), T3 (adubação orgânica com esterco de aves), T4 (adubação orgância com esterco bovino), em 5 repetições, foi realizada análise dos teores de fósforo disponíveis no solo e nas plantas. Os dados foram submetidos a estatística descritiva, análise de variância e as médias comparadas pelo teste de Tukey a $5 \%$ de probabilidade, por meio do software MINITAB ${ }^{\odot}$ versão 18 . Os teores de fósforo no solo aos 10 meses não apresentaram diferenças entre os tratamentos, já para teores de fósforo absorvidos pelas plantas de mandioca e acumulados em folhas, houveram diferenças à 5\% de probabilidade, e o tratamento com adubação de esterco bovino proporcionou uma média de 33,63 $\mathrm{gKg}^{-1}$ na concentração de fósforo, seguido por esterco de aves 24,99 $\mathrm{g} \mathrm{Kg}^{-1}$, adubação NPK 22,57 $\mathrm{gKg}^{-1}$ e sem adubação $15,90 \mathrm{gKg}^{-1}$. Os tratamentos com adubos orgânicos aumentaram os teores de fósforo nas folhas.
\end{abstract}

Palavras-chave: Manihot Esculenta Crantz. Adubos. Fertilidade.

\section{PHOSPHORUS CONTENT POTENTIALLY AVAILABLE IN THE SOIL AND ABSORBED BY MANIOC PLANTS UNDER DIFFERENT SOURCES OF FERTILIZATION IN THE FAMILY AGRICULTURE AREA}

\begin{abstract}
SUMMARY: The objective of this study was to evaluate the rate of absorption of phosphorus in manioc (Manihots Esculenta Crantz) and phosphorus levels potentially available in the soil under different fertilization sources. The experiment was carried out in the community of Boa Esperança using the cultivar Bem-te-vi, in the randomized blocks design with 4 treatments: T1 (No fertilization), T2 (NPK fertilization), T3 (organic fertilization with poultry manure), T4 (organic fertilization with bovine manure), and 5 replicates, an analysis of the available soil and plant phosphorus content was performed. The data were submitted to descriptive statistics, analysis of variance and the means were compared by Tukey test at $5 \%$ probability using the software MINITAB ${ }^{\odot}$ version 18 . The soil phosphorus levels at 10 months did not show differences between treatments, as well as for phosphorus content absorbed by the cassava plants and accumulated in the leaves, there were differences at $5 \%$ probability, in which the treatment with manure of bovine manure provided an average of $33,63 \mathrm{~g} \mathrm{Kg}^{-1}$ in the concentration of phosphorus followed by manure of birds $24,99 \mathrm{gKg}^{-1}$, NPK fertilization $22,57 \mathrm{gKg}^{-1}$ and without fertilization $15,90 \mathrm{gKg}^{-1}$. The treatments with organic fertilizer increased the levels of phosphorus in the leaves.
\end{abstract}

Keywords: Manihot Esculenta Crantz. Fertilizes. Fertility.

\section{INTRODUÇÃO}

A mandioca (Manihot esculenta Crantz.) é um dos alimentos mais energéticos do mundo, sendo consumido por mais de 700 milhões de pessoas, e possui grande importância na dieta alimentar do brasileiro principalmente na região amazônica onde as populações tradicionais

\footnotetext{
${ }^{1}$ Ciências Agrárias/ Agronomia

${ }^{2}$ Agronomia/ Ciência do solo
} 
possuem essa cultura como sua principal fonte de alimento (MURRIETA et al., 2008). A agricultura familiar brasileira, é a grande responsável pelo abastecimento de alimentos no país, sendo que corresponde a $87 \%$ da produção nacional de mandioca (FAO, 2017).

Suas raízes são ricas em carboidratos, podendo ser consumidas frescas, após cozimento, processadas em produtos alimentícios ou em ração animal, seu amido pode ser usado na indústria farmacêutica, em construções de compensado, papel ou bioetanol e suas folhas também são utilizadas em alguns países como alimento (FAO, 2015).

A produção mundial de mandioca para o ano de 2016 foi de 277,1 millhões de toneladas, sendo o Brasil o quarto maior produtor mundial. A safra da produção brasileira da raiz de mandioca em 2019 atingiu 20,08 milhões de toneladas. O Pará é o estado com a maior produção de raiz de mandioca do Brasil sendo 3,96 milhões de toneladas (IBGE, 2020). De acordo com Lima et al. (2012), na Amazônia a mandioca possui além de valor econômico, o cultural, sendo que o produto principal é a farinha.

Embora a mandioca tenha um bom desenvolvimento em condições limitadas como baixa fertilidade do solo e déficit hídrico, esta cultura extrai uma grande quantidade de nutrientes do solo e, as condições deste ambiente em ciclos subsequentes compromete a produtividade da mesma. De acordo com Alves e Júnior (2012), a produtividade está diminuindo, devido a diversos fatores, entre os quais estão: a oferta reduzida de tecnologia e assistência aos produtores.

No estado do Pará um fator limitante para a produção agrícola são as condições naturais de solo, bem como o clima da região, além do manejo inadequado. De acordo com Silva et al. (2012), por apresentar tolerância à seca e à solos de baixa fertilidade, os produtores utilizam quantidades mínimas de insumo ou não utilizam, o que deprecia o potencial da cultura para produção de raízes e parte aérea.

Existem poucos trabalhos com relação a diferentes fontes de adubações para cultura da mandioca, com ênfase na disponibilidade de fósforo (P), sendo fundamental estudos com esta finalidade, haja visto que este é o quarto elemento mais extraído pela cultura. No entanto, alguns trabalhos demonstram que a mandioca responde de forma positiva a adubação, melhorando os teores de nutrientes e o rendimento da cultura (ODEDINA et al., 2011). Sendo que a disponibilidade de nutrientes é afetada por alterações sofridas pelo solo a partir de diferentes práticas de cultivo (PAVINATO et al., 2009).

O fósforo é um elemento essencial para as plantas, mas estar em baixa disponibilidade nos solos brasileiros, assim a adubação fosfatada é uma prática fundamental na agricultura brasileira. Entretanto, o alto valor dos fertilizantes fosfatados oneram os custos de produção (GATIBONI et al., 2015), o que dificulta a aquisição por pequenos produtores rurais. 
Assim, é necessário alternativas de adubação que disponibilize $\mathrm{P}$ em quantidades suficientes para a cultura. Neste sentido, objetivou-se com este trabalho analisar a absorção de fósforo pela planta e disponibilidade no solo sob diferentes fontes de adubação em área de agricultura familiar.

\section{MATERIAL E MÉTODO}

$\mathrm{O}$ experimento foi realizado em área de pequeno produtor familiar, localizada na margem da PA 370, em Curuá-Una, Santarém, PA na mesorregião do Baixo Amazonas. De acordo com a classificação de Koppen, o clima da região é do tipo Ami, sendo um clima tropical com uma estação anual seca bem definida e outra com elevados índices pluviométricos (ANDRADE et al., 2013).

A temperatura média anual é de $25^{\circ} \mathrm{C}$, variando de 18,4 a $32,6{ }^{\circ} \mathrm{C}$, e umidade relativa do ar de $86 \%$ (73-96\%); precipitação anual média de $2.110 \mathrm{~mm}$, com alta pluviosidade entre os meses de março a maio, e baixa pluviosidade de agosto a novembro; com insolação média anual de 2.150 horas e nebulosidade média anual oscilando de 5,6 e 0,6 décimos (CARVALHO, 2000), os dados de precipitação mensal e temperatura durante o período de estudo, são apresentados na Figura 1.

Figura 1. Valores de precipitação, temperatura máxima e temperatura mínima durante o desenvolvimento do experimento.

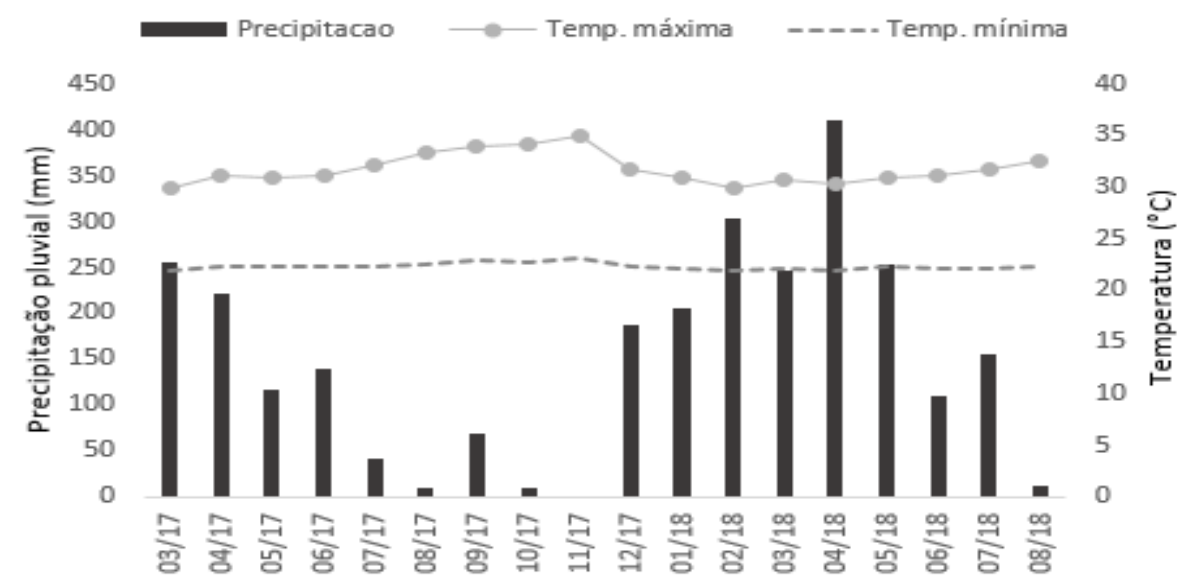

Fonte: Adaptado de INMET (2019).

A pesquisa foi desenvolvida em área experimental na comunidade da Boa Esperança sob as coordenadas $2^{\circ} 44^{\prime} 24,7^{\prime \prime}$ de latitude Sul e $54^{\circ} 31^{\prime} 33,2^{\prime \prime}$ de longitude oeste, apresentando altitude de $145 \mathrm{~m}$, medindo 35 x $28 \mathrm{~m}$, totalizando $980 \mathrm{~m}^{2}$ de experimento, no período de março de 2017 a julho de 2018, em solo de textura muito argilosa. 
Antes do plantio foram coletadas amostras de solo para caracterização química de fertilidade, conforme metodologia da Embrapa (2009a), e de acordo com o resultado obtido (Tabela 1) realizou-se a adubação, conforme Manual para recomendações de adubação e calagem para o estado do Pará (EMBRAPA, 2007a). Foi realizado gradagem no local com o intuito de melhorar as condições físicas do solo.

Tabela 1 - Atributos físicos e químicos do solo antes do plantio.

\begin{tabular}{|c|c|c|c|c|c|c|c|c|c|c|c|c|c|}
\hline Camada & & & & $\mathrm{P}$ & $\mathrm{K}$ & $\mathrm{Ca}+\mathrm{Mg}$ & $\mathrm{Ca}$ & $\mathrm{Mg}$ & $\mathrm{Al}$ & $\mathrm{H}$ & \multirow{2}{*}{\multicolumn{3}{|c|}{$\begin{array}{ll}\text { MO } & \text { SB CTC } \\
\mathrm{g} / \mathrm{dm}^{3} & \mathrm{Cmolc} / \mathrm{dm}^{3}\end{array}$}} \\
\hline \multirow{2}{*}{$0-20$} & $\mathrm{H}_{2}$ & & $\mathrm{CaCl}_{2}$ & \multicolumn{2}{|c|}{$\mathrm{mg} / \mathrm{dm}^{3}$} & \multicolumn{5}{|c|}{ 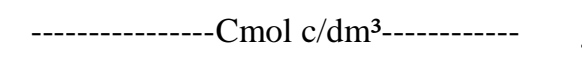 } & & & \\
\hline & 6 , & & 5,4 & 4,0 & 43,9 & 4,7 & 3,4 & 1,2 & 0,0 & 4,0 & 37,8 & 4,8 & 8,7 \\
\hline Camada & \multicolumn{4}{|c|}{ Saturação $(\%)$ por } & \multicolumn{3}{|c|}{ Relações } & & Silte & Argila & $\mathrm{V}$ & $\mathrm{m}^{\mathrm{c}}$ & $\%$ \\
\hline \multirow{2}{*}{$0-20$} & $\mathrm{Ca}$ & & $\mathrm{K}$ & $\mathrm{H}$ & $\mathrm{Ca} / \mathrm{Mg}$ & $\mathrm{Ca} / \mathrm{K} \mathrm{N}$ & $\mathrm{Mg} / \mathrm{K}$ & $--\cdot$ & $\mathrm{g} / \mathrm{Kg}--$ & -------- & ------ & $-\%$ & ---- \\
\hline & 39,0 & & 1,3 & 45,5 & 2,7 & 29,8 & 11,0 & & 168,0 & 659,0 & 54,5 & & 0,0 \\
\hline
\end{tabular}

O experimento foi conduzido com cultivo de mandioca (Manihot esculenta Crantz.), sendo a cultivar utilizada Bem-te-vi, que também é utilizada pelos produtores no local. O material genético para a implantação do experimento foi disponibilizado pelos próprios produtores da comunidade local, sendo selecionados os melhores materiais para a condução do experimento, e realizado o plantio no dia 15 de março de 2017, utilizando o espaçamento de 1 x $1 \mathrm{~m}$.

O delineamento utilizado foi o de blocos casualizados - DBC, sendo quatro tratamentos em 5 blocos, totalizando 20 parcelas, cada parcela tinha $6 \times 6 \mathrm{~m}$, totalizando $36 \mathrm{~m}^{2}$ por parcela. No tratamento 1 (T1), este é o tratamento sem adubação, o tratamento 2 (T2) corresponde a fertilização com NPK, foi realizado adubação conforme recomendado no Manual de adubação e calagem do estado do Pará EMBRAPA (2007b), o tratamento 3 (T3) é referente a adubação orgânica com cama de aviário, sendo $11 \mathrm{Kg} /$ parcela e para o tratamento 4 (T4) correspondente a fonte com esterco bovino, foi utilizado de $16 \mathrm{~kg} /$ parcela.

Para a análise do teor de fósforo nas folhas, de cada parcela experimental foi retirado 35 folhas, sendo 175 por tratamento, totalizando 700 folhas para análise do experimento, coletadas entre os meses de janeiro e fevereiro de 2018, e a análise realizada no mês de março, sendo selecionadas as folhas sadias da parte superior das plantas com as mesmas características.

Posteriormente foram adicionadas em estufa de circulação forçada a $65^{\circ} \mathrm{C}$ por 72 horas e moídas em moinho do tipo Willey, após o processo as amostras foram pesadas $0,5 \mathrm{mg}$, em seguida colocadas em cadinhos de porcelana e levadas à mufla por 3 horas à $550{ }^{\circ} \mathrm{C}$ de temperatura até atingir cinzas, após esse processo adicionou-se $25 \mathrm{ml} \mathrm{de} \mathrm{HNO}_{3} 1 \mathrm{molL}^{-1}$ para determinação do fósforo total. 
Em seguida, foi adicionado em tubo de $30 \mathrm{ml}, 5 \mathrm{ml}$ da solução digerida e $10 \mathrm{ml}$ de solução diluída de molibdato proveniente de solução de molibdato de amônio 2\%, e ácido ascórbico, após 30 minutos foi-se realizado a leitura por espectrofotômetro com o comprimento de onda de $660 \mathrm{~nm}$, sendo utilizado o Modelo Nova 3300UV (EMBRAPA, 2009b).

Para a análise do teor de fósforo no solo, foi coletado no mês de junho de 2018 de cada parcela experimental, 10 amostras simples para formar 1 amostra composta por parcela, totalizando, 20 amostras compostas para o experimento. Para a coleta das amostras foi utilizado trado holandês até a profundidade de $20 \mathrm{~cm}$, sendo colocadas em sacos de $1 \mathrm{~kg}$ para serem transportadas até o laboratório de solos da Ufopa.

Foram peneiradas em malha de $2 \mathrm{~mm}, 10 \mathrm{~g}$ de cada amostra de solo e colocadas para secar em estufa de circulação forçada. Posteriormente foi condicionado em erlenmeyer de $125 \mathrm{ml}$ e adicionado $100 \mathrm{ml}$ da solução extratora de Mehlich 1, e colocadas em agitador magnético orbital, por 5 minutos para posteriormente decantar por 24 horas.

Após decantação, extraiu-se $30 \mathrm{ml}$ do extrato e adicionou-se $10 \mathrm{ml}$ de solução de molibdato de amônio diluída, e adicionou $30 \mathrm{mg}$ de ácido ascórbico, para posterior leitura em espectrofotômetro Modelo Nova 3300UV (EMBRAPA, 2009c).

Os dados foram submetidos à estatística descritiva, análise de variância e as médias dos tratamentos comparadas pelo teste Tukey a 5\% de probabilidade, o software estatístico utilizado foi MINITAB ${ }^{\odot}$ versão 18 .

\section{RESULTADO E DISCUSSÃO}

Com relação a análise descritiva do experimento para fósforo disponível no solo, o desvio padrão foi inferior ao desvio apresentado pela absorção foliar da planta em relação ao nutriente em questão, logo os pontos referentes aos dados estão próximos da média amostral, tendo como 0,790, 0,039 e 4,261 gKg-1 valores médio, mínimo e máximo respectivamente (Tabela 2).

Já para a absorção pela planta, de acordo com o desvio padrão nota-se que os pontos referentes aos dados estão próximos da média amostral, sendo que o valor médio para toda a variável é de 24,27, o valor mínimo referente aos dados é 13,42 e o máximo 43,75 gKg-1. O quartil 1 (Q1) foi de 16,10 e o quartil 3, se deu pelo valor de 30,75. De acordo com Freitas et al. (2018), a utilização de quartis deve representar a primeira e segunda metade da distribuição a partir da mediana respectivamente, portanto é útil na comparação de conjunto de dados. 
Tabela 2 - Análise descritiva dos dados para P no solo e concentrado nas folhas.

\begin{tabular}{cccccc} 
Variável & Média & EP Média & Desvpad & Variância & CoefVar $(\%)$ \\
\hline P DISPONÍVEL & 0,790 & 0,217 & 0,971 & 0,943 & 104,37 \\
P ABSORVIDO & 24,27 & 1,89 & 8,47 & 71,78 & 25,46 \\
\hline Variável & Mediana & Q3 & Máximo & Mínimo & Q1 \\
\hline P DISPONÍVEL & 0,547 & 0,880 & 4,261 & 0,039 & 0,215 \\
P ABSORVIDO & 23,55 & 30,75 & 43,75 & 13,42 & 16,10 \\
\hline
\end{tabular}

Para a análise de dispersão dos dados para a variável fósforo disponível no solo, de acordo com a figura 2, nota-se que não houve grande dispersão dos dados para cada tratamento, com excessão do tratamento referente a adubação mineral NPK.

Figura 2. Dispersão dos dados referentes aos tratamentos para fósforo disponível.

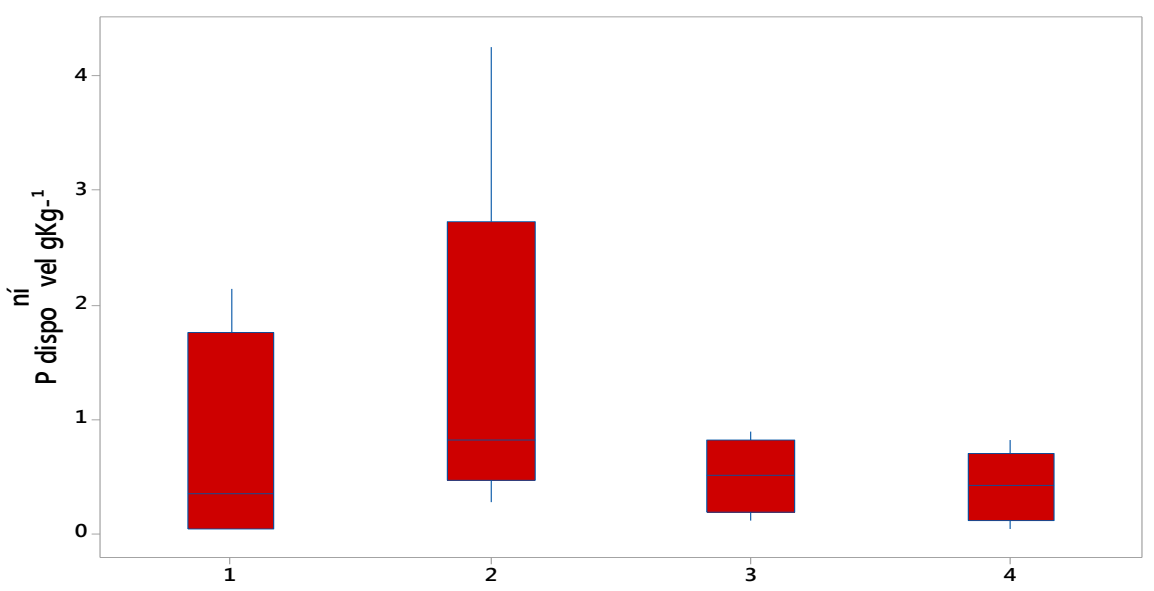

A medida de dispersão tem por objetivo expressar de forma visual como as observações se distribuem em um conjunto de dados, para saber se estão próximos entre si nas amostras estudadas ou estão afastadas (BASTOS; DUQUIA, 2007).

Com relação ao gráfico de dispersão dos dados para absorção de fósforo nas folhas de mandioca, foi observado que houve uma dispersão superior a observada com relação ao teor do elemento no solo, a Figura 3, demonstra que entre os tratamentos houve uma variação aceitável, cujo coeficiente de variação foi de $25,46 \%$ para o experimento.

A distribuição dos dados referentes ao tratamento 1 é homogêneo cujos valores das amostras ficam dispersas numa faixa de 15 a $18 \mathrm{gKg}^{-1}$. Para os demais conjuntos de dados em relação a cada tratamento, o gráfico de dispersão demonstra que há uma determinada variação para os tratamentos 2 e 4 a partir de suas amostras, mas é considerado aceitável. 
Figura 3. Dispersão dos dados referentes aos teores de fósforo absorvidos em detrimento dos tratamentos.

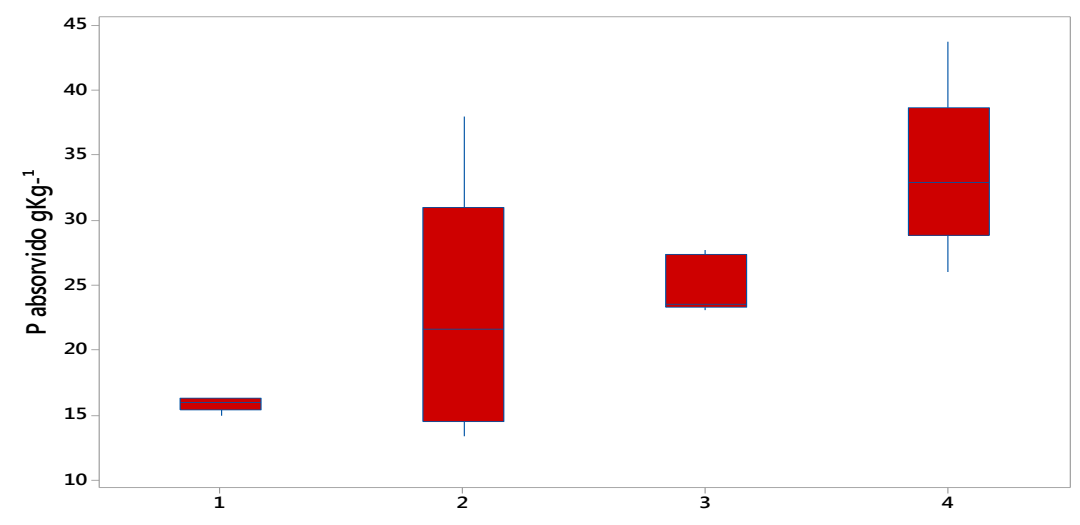

A Figura 4 representa os valores referentes entre as taxas de concentração de fósforo disponível no solo e o teor absorvido pelas folhas da cultivar, logo nota-se uma diferença entre as quantidades.

A concentração final de fósforo nas folhas até o momento da análise foi superior à concentração de fósforo no solo. Conforme Pereira et al. (2012), a planta precisa absorver o fósforo a medida que se tenha disponibilidade no solo como estratégia para compor a parte aérea principalmente na fase inicial de desenvolvimento, que de acordo com Viana et al. (2001), estar ligado ao processo fotossintético da planta para se ter acúmulo de carboidratos que serão distribuídos para as raízes

Figura 4. Representação da taxa de concentração de P na folha e solo.

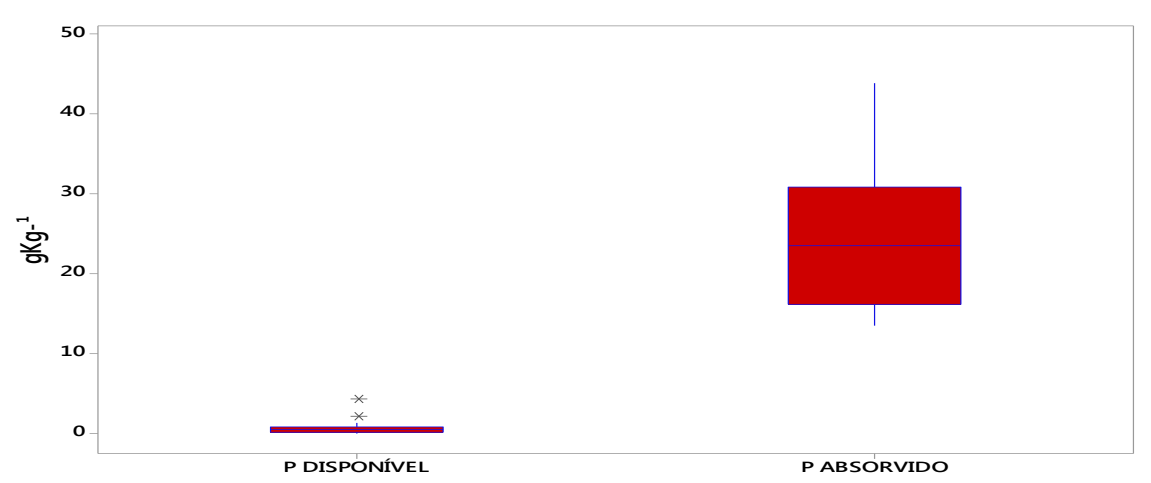

Com relação a disponibilidade de fósforo no solo, foi observado valores baixos quando comparados à absorção pela planta, com o tempo a planta tende a retirar de forma eficiente o P do solo. Frazão et al. (2008), afirma que a utilização de adubos orgânicos ocasiona reflexos diretos e indiretos sobre as características químicas do solo, devido ao aumento da capacidade de troca de cátions com maior disponibilidade de nutrientes para a planta devido ao acúmulo de material orgânico. 
Segundo Paulo (2018), a cultura da mandioca retira uma grande quantidade de nutrientes disponíveis no solo, deixando-o com valores baixos desse nutriente, sendo necessária a devolução desse elemento a cada ciclo da cultura.

Para o teste de comparação do teor de fósforo absorvido pela planta e acumulado na folha, nota-se que houve diferenças significativas $(\mathrm{p} \leq 0,05)$ entre os tratamentos, sendo o tratamento proveniente de adubação orgânica com esterco de bovino superior aos demais na concentração de fósforo, e diferiu do tratamento sem adubação, sendo igual ao tratamento com adubação cama de aviário e adubação mineral N-P-K, conforme identificado na Tabela 3 respectivamente.

Tabela 3 - Média absorvida para cada tratamento na planta.

\begin{tabular}{lcc}
\hline \multicolumn{1}{c}{ Tratamentos } & $\begin{array}{c}\text { P absorvido pela planta } \\
\text { gkg }^{-1}\end{array}$ & $\begin{array}{c}\text { P disponível no solo } \\
\text { gkg-1 }^{-1}\end{array}$ \\
\hline Sem adubação & $15,90 \mathrm{~B}$ & $0,79 \mathrm{~A}$ \\
Adubação mineral N-P-K & $22,57 \mathrm{~A} \mathrm{~B}$ & $1,45 \mathrm{~A}$ \\
Adubação orgânica Cama de aviário & $24,99 \mathrm{~A} \mathrm{~B}$ & $0,51 \mathrm{~A}$ \\
Adubação orgânica Esterco de bovino & $33,63 \mathrm{~A}$ & $0,41 \mathrm{~A}$ \\
\hline C.V(\%) & 25,46 & 104,37 \\
\hline
\end{tabular}

Médias seguidas pela mesma letra não diferem entre si pelo teste de Tukey $(\mathrm{p} \leq 0,05)$.

Os valores encontrados aos 10 meses de avaliação foram considerados altos, atingindo $33,63 \mathrm{gKg}^{-1}$ de fósforo. $\mathrm{O}$ teor de fósforo nas folhas ideal para plantas de mandioca, deve ser de 3 - $5 \mathrm{gkg}^{-1}$ considerando amostragens entre os três a quatro meses de idade (MALAVOLTA et al., 1997). A determinação do teor de nutrientes requeridos pelas plantas deve ser feita a partir de diferentes fases de desenvolvimento através da quantificação absorvida pelo orgão da planta, sendo importante para o diagnóstico do estado nutricional (SILVA et al., 2014).

Tais resultados estão relacionados à época de coleta do material para análise. Wobeto et al. (2006), estudando a concentração de nutrientes em folhas de diferentes cultivares de mandioca, demonstra que a concentração nos teores de nutrientes possui taxa de variação de acordo com características genéticas das cultivares e a maturidade vegetal, sendo encontrado maiores teores de fósforo a partir dos 12 meses.

$\mathrm{Na}$ adubação mineral com NPK, enquanto o $\mathrm{N}$ e $\mathrm{K}$ permanecerem em formas que as raízes podem aproveitar durante um período mais longo, o $\mathrm{P}$ é liberado com uma maior facilidade ao solo e assim, tende a reagir com os componentes presentes no mesmo, podendo ser convertido em formas que a planta não consiga absorver, ou quando absorve é com dificuldade.

O P tem baixa mobilidade no solo, principalmente em solos ácidos e ricos de óxihidróxidos de $\mathrm{Fe}$ e $\mathrm{Al}$ o que facilita sua acumulação em formas indisponíveis para as plantas 
(OLIVEIRA et al., 2014), tais características são encontradas na maioria dos solos da região Norte.

Com relação ao teste de comparação de médias para a variável P disponível no solo, foi observado que não houve diferenças significativas entre os tratamentos analisados, mas foi constatado que a adubação mineral NPK obteve a maior média de disponibilidade, seguido pelo tratamento sem adubação e cama de aviário, respectivamente.

Estudos realizados por Rós et al. (2013), demonstram efeito positivo na disponibilidade de fósforo com adição de esterco, sendo que o teor aumentou de $39 \mathrm{mgdm}^{-3}$ sem adição de esterco para $145 \mathrm{mgdm}^{-3}$ a partir de $18 \mathrm{t} \mathrm{ha}^{-1}$ de esterco. Villani et al. (2009), afirmam que o processo de liberação de $\mathrm{P}$ para a solução do solo estar relacionado ao processo de mineralização pelas células microbianas, reduzindo a adsorção pelo solo.

Apesar de os valores para fósforo serem baixos conforme tabela 3, isso pode estar relacionado á época de coleta do solo, além de características próprias da cultivar e do solo. De acordo com Rós et al. (2017) a concentração de fósforo nas camadas superficiais, nem sempre vai garantir a disponibilização total do nutriente para a planta.

Quando comparado ao teste para absorção, nota-se que há uma interação entre o fósforo disponível no solo e o teor presente nas folhas das plantas, portanto o tratamento na variável absorção, o T4 que foi a fonte mais absorvível, no período final do experimento na variável disponibilidade no solo, foi a que obteve a menor taxa de fósforo disponível, sendo que para cama de frango se obteve resultados semelhantes, conforme Figura 5. Valadão et al. (2011) afirma que a utilização de cama de frango aumenta o teor de disponibilidade de nutrientes no solo. Contudo, observa-se que basicamente todo $\mathrm{P}$ que estava disponível no solo, foi absorvido pela planta, sendo necessária sua reposição.

Já para tratamento com NPK, os resultados demonstram maior teor de disponibilidade no solo no período final de avaliação, isso devido a planta não ter absorvido uma grande quantidade de fósforo dessa fonte. Essas diferenças encontradas, provavelmente, são inerentes à cultivar e devido à idade da planta e à maturidade das folhas. 
Figura 5. Interação entre as variáveis $\mathrm{P}$ absorvido pela planta e disponível no solo.

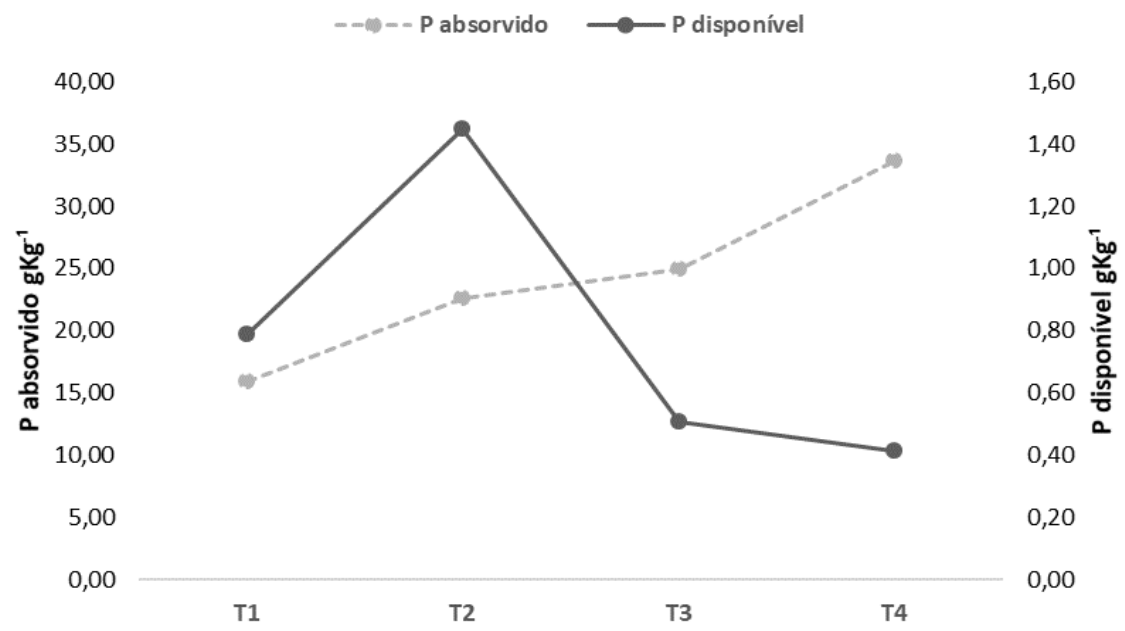

Portanto, a partir da utilização de diferentes fontes de adubos, nota-se que a disponibilidade de fósforo tem influência positiva na absorção pela planta e disponibilidade no solo, sendo que a adubação com esterco bovino e cama de frango, aumentaram os níveis de fósforo nas folhas devido a lenta disponibilidade de nutrientes destas fontes. De acordo com Nascimento et al. (2014) a adubação orgânica aumenta o desenvolvimento das plantas de mandioca, melhorando os atributos químicos, físicos e biológicos do solo.

Tais resultados corroboram com trabalhos realizados a partir de fontes de esterco bovino, em que houve melhorias na qualidade do solo, com posterior acúmulo de nutrientes na parte aérea, e raízes das plantas (BELTRÃO et al. 2008; MENEZES; SILVA, 2008; DEVIDE et al., 2009). Já para o tratamento com adubação NPK devido a rápida disponibilidade do elemento e adsorção pelas partículas do solo, a planta não absorveu grandes quantidades.

\section{CONCLUSÃO}

O fósforo disponível no solo aos 10 meses de cultivo de mandioca foi semelhante para diferentes fontes de adubações, sendo que as plantas absorveram maiores teores de fósforo nos tratamentos com adubações orgânicas de cama de aves e esterco bovino. As fontes orgânicas apresentaram maior potencial de disponibilidade para as plantas de mandioca.

\section{REFERENCIAS}

ALVES, R. N. B.; JÚNIOR, M. S. M. Custo e rentabilidade do processamento de farinha de tapioca no distrito de americano, no município de Santa Isabel, Pará. Amazônia: Ciência e Desenvolvimento, v.8, n.15, p. 91 - 102, 2012. 
ANDRADE, S. C. P.; VALMIR ROCHA VIEIRA, V. R.; MORAIS, H. F.; ALBUQUERQUE, E. M.; SANTOS, C. A. C. Estimativa de albedo, NDVI e Temperatura de Superfície no município de Santarém-PA. Anais XVI Simpósio Brasileiro de Sensoriamento Remoto - SBSR, Foz do Iguaçu, PR, Brasil, 2013.

BASTOS, J. L. D.; DUQUIA, R. P. Medidas de dispersão: os valores estão próximos entre si ou variam muito. Scientia Medica, v.17, n.1, p. 40 - 44, 2007.

BELTRÃO, F. A. S.; PIMENTA FILHO, E. C.; PAES, R. A.; SOLTO, J. S.; MADALENA, J. A. S. Comportamento de maniçoba (Manihot pseudoglaziovii Muell. Arg.) sob diferentes espaçamentos e adubações. Revista Caatinga, v.21, n.4, p. 163 - 166, 2008.

CARVALHO, J. O. Classificação em grupos ecológicos das espécies mais importantes em uma área da Floresta Nacional do Tapajós, Belterra, PA, 2000. Disponível em: <

https://www.infoteca.cnptia.embrapa.br/handle/doc/381288> . Acesso em: 12 jul. 2018.

DEVIDE, A. C. P.; RIBEIRO, R. L. D.; VALLE, T. L.; ALMEIDA, D. L.; CASTRO, C. M.; FELTRAN, J. C. Produtividade de raízes de mandioca consorciada com milho e caupí em sistema orgânico. Bragantina, v.68, n.1, p. 145 -153, 2009.

EMBRAPA - EMPRESA BRASILEIRA DE PESQUISA AGROPECUÁRIA. Recomendações de adubação e calagem para o estado do Pará. Editores técnicos: CRAVO, M.S.; VIEGAS, I.J.M.; BRASIL, E.C. Belém, PA. Embrapa Amazônia Oriental. 2007. 262p.

EMBRAPA - EMPRESA BRASILEIRA DE PESQUISA AGROPECUÁRIA. Centro Nacional de pesquisa de solos. Manual de análises químicas de solos, planta e fertilizantes. $2^{\mathrm{a}}$ ed., Brasília, 2009. 627p.

FAO - ORGANIZAÇÃO DAS NAÇÕES UNIDAS PARA AGRICULTURA E ALIMENTATAÇÃO, 2015. Dados de produtividade de 2014. Disponível em: < http://www.fao.org/brasil/pt/>. Acesso em: 28 de mar. 2018.

FAO - ORGANIZAÇÃO DAS NAÇÕES UNIDAS PARA AGRICULTURA E ALIMENTATAÇÃO, 2017. Disponível em: < http://www.fao.org/brasil/pt/>. Acesso em: 28 de jul. 2018.

FRAZÃO, L. A.; PÍCCOLO, M. C.; FEIGI, B. J.; CERRI, C. C.; CERRI, C. E. P. Propriedades químicas de um neossolo quatzarênico sob diferentes sistemas de manejo no cerrado matogrossense. Pesquisa Agropecuária brasileira, v.43, n.5, p. 641 - 648, 2008.

FREITAS, A.; FIGUEIREDO, T. S.; SILVA, N.; MIRANDA, M. C. Dificuldades na aprendizagem da mediana e quartis por alunos do $8^{\circ}$ ano de escolaridade: estudo comparativo fórmula versus gráfico. Indagatia Didactica, v.10, n.2, p. 109 - 132, 2018.

GATIBONI, L. C.; SMYTH, T. J.; SCHMITT, D. E.; CASSOL, P. C.; OLIVEIRA, C. M. B. Limite crítico ambiental de fósforo para solos Sul-brasileiro com adição de altas doses de nutrientes. In: Tópicos em ciência do solo, vol. IX, Viçosa: Sociedade Brasileira de Ciência do Solo, p. $144-168,2015$.

IBGE - Instituto Brasileiro de Geografia e Estatística. Levantamento Sistemático da Produção Agrícola, 2020. Disponível em < https://www.ibge.gov.br/estatisticas/economicas/agricultura-epecuaria/9201-levantamento-sistematico-da-producao-agricola.html?=\&t=o-que-e >. Acesso em: 16 fev. 2020. 
INMET - Instituto nacional de Meteorologia, 2018. Disponível em < http://www.inmet.gov.br/portal/index.php?r=tempo/graficos>. Acesso em: 15 mai. 2019.

LIMA, D.; STEWARD, A.; RICHERS, B. T. Trocas, experimentações e preferências: um estudo sobre a dinâmica da diversidade da mandioca no médio Solimões, Amazonas. Boletim do Museu Paraense Emílio Goeldi. Revista Ciências Humanas, v. 7, n. 2, p.371-396, 2012.

MALAVOlTA, E.; VITTI, G. C.; OLIVEIRA, S. A.; Avaliação do estado nutricional das plantas: princípios e aplicações. 2. ed. Piracicaba: Potafos, 1997. 319 p.

MENEZES, R. S. C.; SILVA, T. O. Mudanças na fertilidade de um neossolo regolítico após seis anos de adubação orgânica. Revista Brasileira de Engenharia Agrícola e Ambiental, v.12, n.3, p. $251-257.2008$.

MURRIETA, R. S. S.; BAKRI, M. S.; ADAMS, C.; OLIVEIRA, P. S. S.; STRUMPF, R. Consumo alimentar e ecologia de populações ribeirinhas em dois ecossistemas amazônicos: Um estudo comparativo. Revista de Nutrição, v.21, p. 123 - 133, 2008.

NASCIMENTO, J. M. L.; SANTOS, M. R. B.; QUEIROZ, M. A. A.; YANO-MELO, A. M. Desenvolvimento vegetativo e associação micorrízica em plantas de mandioca adubadas com resíduo agroindustrial. Semina: Ciências Agrárias, v.35, n.2, p. 727 - 734, 2014.

ODEDINA, J. N.; ODEDINA, S. A.; OJENIYI, S. O. Effect of types of manure on growth and yield of cassava (Manihot esculenta Crantz). Researcher, v.3, n.5, p.1 - 8, 2011.

OLIVEIRA, L. B.; TIECHER, T.; QUADROS, F. L. F.; TRINDADE, J. P. P.; GATIBONI, L. C.; BRUNETTO, G.; SANTOS, D. R. Formas de fósforo no solo sob pastagens naturais submetidas à adição de fosfatos. Revista Brasileira de Ciência do Solo, v.38, n.3, p. 867 - 878 , 2014.

PAULO, R. G. Manejo de adubação na cultura da mandioca (Manihot esculenta Crantz). 2018. 29 f. Dissertação (Graduação em agronomia)- Centro de ciências agrárias, Universidade Federal da Paraíba, Paraíba, 2018.

PAVINATO, P. S.; MERLIN, A.; ROSOLEM, C. A. Disponibilidade de cátions no solo alterada pelo sistema de manejo. Revista Brasileira de Ciência do solo, v.33,n.4, p. 1031 - 1040, 2009.

PEREIRA, G. A. M.; LEMOS, V. T.; SANTOS, J. B.; FERREIRA, E. A.; SILVA, D. V.; OLIVEIRA, M. C.; MENEZES, C. W. G. Crescimento da mandioca e plantas daninhas em resposta a adubação fosfatada. Revista Ceres, v.59, n.5, p. 716 - 722, 2012.

RÓS, A. B.; HIRATA, A. C. S.; NARITA, N. Produção de raízes de mandioca e propriedades química e física do solo em função de adubação com esterco de galinha. Pesquisa Agropecuária Tropical, v.43, n.3, p. $247-254,2013$.

RÓS, C. O.; SILVA, V. R.; SILVESTRIN, T. B.; SILVA, R. F.; PESSOTTO, P. P. Disponibilidade de nutrientes e acidez do solo após aplicações sucessivas de água residuária de suinocultura. Revista Brasileira de Tecnologia Agropecuária, v.1, n.1, p. 35 - 44, 2017.

SILVA, A. F.; OLIVEIRA, D. S.; SANTOS, A. P. G.; SANTANA, L. M.; OLIVEIRA, A. P. D. Produção da parte aérea de variedades de mandioca em Petrolina-PE. In: II Congresso Brasileiro de Recursos Genéticos, 2012. 
SILVA, H. R. F.; MELO, V. L.; PACHECO, D. D.; ASSIS, Y. J. M.; SALES, H. R. Acúmulo de matéria seca e micronutrientes em mandioca consorciada com bananeira. Pesquisa Agropecuária Tropical, v.44, n.1, p. 15 - 23, 2014.

VALADÃO, F. C. S.; MAAS, K. D. B.; WEBER, O. L. S.; JÚNIOR, D. D. V.; SILVA, T. J. Variação nos atributos do solo em sistema de manejo com adição de cama de frango. Revista Brasileira de Ciência do Solo, v.35, n.6, p. 2073 - 2082, 2011.

VIANA, A. E. S.; SEDIYAMA, T.; LOPES, S. C.; CECON, P. R.; SILVA, A. A. Efeito do comprimento e de incisões no córtex da maniva sobre o cultivo da mandioca (Manihot esculenta Crantz). Acta Scientiarum Agronomy, v.23, n.5, p. 1263 - 1269, 2001.

VILLANI, E. M. A.; BARROS, N. F.; NOVAIS, R. F.; MENDONÇA, E. S.; ZOCOLO, G. J. Determinação de fósforo microbiano: comparação entre métodos e coberturas vegetais. Revista Brasileira de Ciência do Solo, v.33, n.4, p. 1061 - 1069, 2009.

WOBETO, C.; CORREAA, A. G.; ABREU, C. M. P.; SANTOS, C. D.; ABREU, J. R. Nutrientes na farinha de folhas de mandioca (Manihot esculenta Crantz) em três idades da planta. Food Science and Technology, v.26, n.4, p. 865 - 869, 2006. 